\title{
Mental health crisis and spatial accessibility to mental health services in the City of Toronto: A geographic study
}

\author{
Original Research \\ Lu Wang ${ }^{1}$, Joseph Ariwi ${ }^{1}$ \\ ${ }^{1}$ Department of Geography, Ryerson University, Toronto, Ontario, Canada \\ Corresponding author: L Wang (luwang@ryerson.ca)
}

\begin{abstract}
Mental illness includes a wide range of disorders that affect mood, thinking, behaviour and overall wellbeing. One in five Canadians has mental health disorder, with a low utilization rate for mental health service. Within the City of Toronto, the provision of specialized mental health care is delivered by over 100 public and private community service organisations and over 700 physicians with a psychiatric specialization - each providing community-based general or specialised care to residents in need. Research has shown that travel distance is an enabling factor of health service utilisation, thus equitable spatial access to services remains a key priority. Using spatial quantitative methods, this study examined potential spatial accessibility to both general and specialized mental health services within the City of Toronto, and levels of statistical association between access to care and prevalence of mental health crisis events. The main datasets analyzed include geo-referenced Census data and occurrence data on mental health crisis (represented by apprehensions under the Mental Health Act undertaken by the Toronto Police Service). The enhanced two-step floating catchment area (E2SFCA) method was used to model spatial accessibility to mental health services based on four modes of transportation: driving, walking, cycling and public transit. Areas that are underserved by mental health specialists and mental health community services were identified and shown to have different socioeconomic characteristics. The study revealed spatially explicit patterns of access to various mental health services in Toronto, providing detailed information to inform the planning of and policy on mental health care delivery concerning severe mental health crisis.
\end{abstract}

\section{KEYWORDS}

Health Care Delivery, Mental Health Crisis, Patterns of Access, Spatial Accessibility

\section{INTRODUCTION}

The global burden of mental illness accounts for $32.4 \%$ of years lived with disability and $13.0 \%$ of disability-adjusted life-years (Vigo et al., 2016). In Canada, mental disorders affect just under $20 \%$ of people (Smetanin et al., 2015). However, the rate of mental health service utilization is only $9.5 \%$ nationally and $8.7 \%$ in the province of Ontario (Vasiliadis et al., 2005). Mental health services are delivered in Canada primarily through various interconnected service providers, including community organizations that provide information, counselling, therapy, treatment, medication and other related services to the general population (Jorm, 2012), primary care practitioners (or family physicians) who are gate keepers to specialists (Fleury et al., 2008), and psychiatric specialists who work in private practices or hospitals (Kates et al., 2011). Family physicians are the main entry point for patients with mental illness into the Canadian healthcare system (Kates et al., 1997; Kates et al., 2011). Patients with severe mental disorder are often transferred to specialized care or collaborative mental health care involving primary care and mental health care specialists (Fleury et al., 2012). 
Community based mental health services frequently involve case management to provide coordinated care to individuals of different backgrounds with various mental illness conditions, which has proven to be uniquely effective in improving treatment outcome, reducing frequent emergency department visits and ensuring continuity of care (Durbin et al., 2016; Stergiopoulos et al., 2016).

In Canada where the health care system is publicly funded, insurance-based barrier to mental health services is often considered less important than in a private health care system. However, many other barriers still exist for individuals in accessing and utilizing mental heath services (Thomson et al., 2015; Wang, 2015; Ng and Zhang, 2020). Alongside a lack of funding and the culture of health care services, geographic disparities in access to mental health services is a key barrier to mental health care in Canada (Kates et al., 2011). Mental health services are not distributed evenly in space, which can result in under-serviced neighbourhoods in socioeconomically disadvantaged areas (Ngui and Vanasse, 2012). Geographic access to service providers and local availability of care have been identified as important factors that influence the utilization of mental health services and mental health outcomes (Fortney et al., 1999; Ghorbanzadeh et al., 2020). Other major barriers to effective mental health services include a lack of mental health literacy and stigma that widely exists in culturally diverse populations. Limited mental health literacy often impedes early intervention and treatment that improve mental health outcomes (Jorm, 2012). Mental illness stigma, often perpetuated by cultural factors, is another profound barrier leading to undesirable consequences such as avoiding treatment, delaying in care seeking from specialized mental health professionals and dropping out prematurely (Kirmayer et al., 2011; Corrigan et al., 2014 Bracke et al., 2019). In Canada, community-based mental health services provide a range of care and support to the general population such as case management, counselling, therapy, treatment, medication, crisis intervention, care coordination and other social and health services as needed, on an outpatient basis. They play an increasingly important role in improving mental health literacy, addressing cultural stigma related to mental illness and facilitating professional help seeking for individuals suffering from mental illness (Jorm, 2012; Stergiopoulos et al., 2016).
Past research has established considerable evidence of the neighbourhood effect on health including mental health, mental disorder and stress (Mair et al., 2010; Hong et al., 2014; Brisson et al., 2014; Snedker and Herting, 2016). Geographical variation in health can be explained by both compositional effects resulting from differences in individuals, which represent many of the well-studied social determinants of health (Bryant et al., 2011; Fryers and Brugha, 2013), and contextual effects reflecting different physical and social attributes of a neighborhood or local environment. Neighbourhood contextual environment, such as walkability and access to amenities, residential density, crime and safety, land-use mix, ethnic concentration, has the potential to promote or negatively affect health and mental health outcomes (Mair et al., 2010; Kim, J. 2010; Lorenc et al., 2012). Past research reveals specific neighbourhood-level factors, such as ambient noise (Tzivian et al., 2015), access to green space and recreational space (Beyer et al., 2014), neighbourhood socioeconomic conditions (Wang and Lara Palacios, 2017), unemployment (McKee-Ryan et al., 2005; Paul and Moser, 2009) and social inequalities (Allen et al., 2014), as significant contributors to symptoms of depression, anxiety and other mental illnesses. As a key neighbourhood characteristic, geographic proximity to mental health services is largely understudied, despite that distance is viewed as an enabling factor in health service utilisation (Fleury et al., 2012).

Spatial accessibility, or geographical accessibility, refers to the relative ease with which individuals from one location can reach other specified locations, and can be measured by distance-based and geographical models such as the two-step floating catchment area model and its variations (Guagliardo, 2004; Wang and Luo, 2005; McGrail and Humphrey, 2009; Wang and Roisman, 2011; Ngui and Vanasse, 2012; Fernandes et al., 2013; Norris et al., 2014; Luo, 2016, Shah et al., 2016). By using accessibility as an analytical framework, past research examines healthcare shortage areas, assesses the relationship between healthcare provision by (hospitals, physicians, pharmacies) and the demand for such services (Wang and Luo, 2005; Ngui and Vanasse, 2012; Elliott and Hunsley, 2015; Cao et al., 2016; Donohoe et al., 2016; Wang and Ramroop, 2018; Farber et al., 2014; Neutens, 2015). For example, access to primary health care is found to vary by residential neighbourhood, leading to health inequalities, and 
health care use and disease burden increase as the distance between home and physicians increases (Billi et al., 2007; Bell et al., 2013). Compared to research on other types of health services, considerably less attention has been focused on geographic accessibility to mental health services and how it relates to mental health outcome.

\section{Study area and research objectives}

Given the social and scholarly contexts, this study sought to examine the spatial accessibility to mental health services provided by community service organizations and physician specialists in the City of Toronto and explore the relationship between service accessibility and the prevalence of mental health crisis events in the City of Toronto (hereafter Toronto). Toronto is the largest metropolitan area in Canada with a population of over 2.5 million people. It has the highest population density in Canada and a high level of socioeconomic and cultural diversity. The provision of specialized mental health services in Toronto is delivered primarily by over 100 public and private community service providers and organisations, as well as over 700 physicians with a psychiatric specialization - each providing community-based general or physician-based specialised mental health $(\mathrm{MH})$ services to residents in need. Despite the availability of various $\mathrm{MH}$ services in Toronto, there is a large number of individuals who experience severe mental health crises due to mental illness. In Toronto and across Canada, police have increasingly become the first responders to mental health calls (Lamb et al., 2002; Coleman and Cotton 2016). The Toronto Police Service is dispatched to over 20,000 calls for service annually related to a person in mental health crisis, 8,000 of which require an apprehension under the Mental Health Act. Unfortunately, some of these calls involve the application of lethal force by the police that resulted in the death of the person in crisis (Borum, 2000). These events prompted the creation of an independent review conducted by Frank lacobucci for the Chief of the Toronto Police Service. The review titled 'Police Encounters with People in Crisis' (lacobucci, 2014), often referred to as the lacobucci Report, had the mandate of reviewing the practices of the Toronto Police Service with respect to lethal force especially in encounters with 'persons who are or may be emotionally disturbed, mentally disturbed or cognitively impaired'. One of the findings in the report highlights the need for mental health services to be delivered to the city's population through mental health community services and mental health specialists to reduce the prevalence of severe mental health episodes that require police intervention. In this regard, the study provides important insights into the understanding of the spatial equity in the provision and use of mental health services.

More specifically, the study aimed to achieve two objectives: 1) quantitatively measure the levels of spatial accessibility to the two forms of mental health services at the level of dissemination area (DA); and 2) assess the spatial relationship between service accessibility and the prevalence of mental health crises. The study used a diverse range of datasets including mental health crisis data provided by Toronto Police Service, location of psychiatrists obtained from Canadian Medical Directory, location of mental health community services from Toronto 211 website, geo-referenced Canadian census and geospatial travel network data. An enhanced twostep floating catchment area (E2SFCA) method was used to model spatial accessibility to mental health services at the DA level (the finest geographical area in the Canadian census), based on four modes of transportation (driving, walking, biking and public transit) and for community $\mathrm{MH}$ services and psychiatrist separately. Combined accessibility scores were calculated by weighing the standardized accessibility score access scores based on modes of transportation. Local Bivariate Moran's I analysis was then used to explore the potential spatial match (and mismatch) between accessibility and occurrences of mental health crises. The study helped to identify under-serviced neighbourhoods with limited levels of spatial accessibility to different types of mental health services. It provided practical implications in service planning in delivering mental health services among neighbourhoods in high needs.

\section{Description of datasets used in spatial analysis}

Data on mental health crisis at the DA level for the City of Toronto, from 2014 to 2016, was obtained from the Toronto Police Service. In this study, a mental health crisis refers to any incident that results in an apprehension that is carried out under the Mental Health Act (MHA) law enforcement where the person in crisis has become a threat to themselves or others (Gray et al., 2008). MHA apprehensions represent extreme events where an individual is 
apprehended to prevent themselves from causing harm to themselves or others. The mental health crisis data used in the study thus contains the occurrences of MHA apprehension at the DA level based on the apprehended person's residential address. Prevalence of mental health crisis was calculated by dividing counts of MHA apprehension by the DA's total population. Z score was further calculated for each DA to give a mental health crisis score that represents the level of mental health crisis severity for the DA. A three-year average from 2014 to 2016 was used in mapping and spatial analyses. For reasons of confidentiality, any personal information such as age, gender and other characteristics of the individual under MHA apprehension was not released.

Data on mental health services include two forms of service providers: community mental health services and physicians specialized in psychiatry. Community-based $\mathrm{MH}$ services provide information, counselling, therapy, treatment, medication and other services, on an outpatient basis, to the general population. Information on the location of mental health community services was extracted from the 211 Toronto website, a directory of community services in the City of Toronto (2017). Psychiatrists are considered mental health specialists providing diagnosis and treatment of mental disorders to patients that have received a referral from their family doctor or hospital. Those who have experienced a mental health crisis and have been apprehended under the MHA are individuals in high needs of service from mental health specialists. The psychiatrists within the study area are located both in private clinics and public hospitals. This data was extracted from the Canadian Medical Directory (2011), a database that provides the names, address, postal codes, contact information, specialization and other details of medical physicians in Canada. The data on $\mathrm{MH}$ community service organizations and practicing psychiatrists were geocoded using street addresses within Arc Map, a Geographic Information System.

Data on population comes from geo-referenced census at the DA level. In Canadian census, DAs are the smallest geographic unit with a total population of 400 to 700 people. The DA boundary shapefiles and census data were retrieved from 2011 CensusPlus (Environics Analytics, 2016), an enhanced census database that incorporates the National Household
Survey and the most recent census data available at the time of the study. The census variables used in the study included the total population above the age of 15 (which represents demand at DA centroid for mental health services), the proportion of the population above the age 15 that travel to work by car, bike, walking and public transit, respectively (which is reflected in calculating spatial accessibility), and average household income (which is a key indicator of the socioeconomic status of population).

Data on travel networks include datasets on the Toronto Centerline, Sidewalk Inventory, Toronto Bikeways and TTC Routes and Schedules from the Toronto Open Data catalogue (City of Toronto, 2017). Four separate transport networks were built. They are polyline shapefiles depicting roads, sidewalks, bikeways and public transit routes for four modes of transportation: driving, walking, biking and public transit. The polyline files for each mode of transportation were queried to only include the transportation lines relevant to the study. For example, for the Toronto Centerline data set, any centerlines that represent features on which automobiles cannot legally drive were removed. Features removed included private laneways, walking paths and coastline boundaries. Likewise, for the bikeways data set, features such as highways and expressways that do not allow cyclist access was removed. For the sidewalk data set, any roadways with incomplete or no sidewalks were removed. For the public transit data set, no public transportation routes were removed.

\section{METHODS}

In order to address the study objectives, spatial accessibility to mental health service locations was first calculated using the enhanced 2-Step Floating Catchment Area (E2SFCA) method at a dissimilation area (DA) level. Further, combined accessibility was calculated to provide a composite score weighted by population in a DA that use different transportation modes (driving, walking, biking and public transit). The bivariate association between the combined accessibility index and prevalence of mental health crisis is assessed by using Pearson's correlation and bivariate local indicator of spatial association (BiLISA).

\section{E2SFCA Model}


The main spatial model used in this study is the enhanced 2-Step Floating Catchment Area (E2SFCA) method to calculate geographic accessibility to mental health services, implemented in Arc Map, for $\mathrm{MH}$ community services and specialist physicians, separately. Built upon the original 2SFCA model, the E2SFCA model was chosen for its ability to calculate geographic accessibility for small area geographies for multiple modes of transportation across a large study area (Luo and Qi, 2009). The E2SFCA model used in this study takes as input three datasets: point locations representing supply (e.g., geocoded physicians), point locations representing demand (e.g., population associated with DA centroids), and travel networks that depict the pathways allowing populations that require mental health services to travel to mental health service locations. The model essentially calculates the ratio of potential demand to amount of physicians or community services, using user-defined catchment areas based on travel distance that is input as a parameter. An additional input parameter for the method is a distance-decay function to account for friction to travel with increased distance.

$$
R_{j}=\frac{S_{j}}{\sum_{k \in\left\{d_{k j} \in D_{r}\right\}} P_{k} W_{r}}
$$

The first step of the E2SFCA model is shown in Equation (1), where $R_{j}$ calculates the ratio between $\mathrm{MH}$ service provider to population (e.g., physician-topopulation ratio) within the catchment area of service provider at location $j . P_{k}$ is the population of DA $k$ falling within the catchment area of ${ }_{j}$. DA centroids represent the points of service demand for each $D A$. $S_{j}$ represents the number of service providers at location $j . d_{k j}$ denotes travel time between $\mathrm{k}$ and j. Dr refers to the $r$ th travel time zone in the catchment, and $W r$ is the distance weight that represents the distance decay of access to service provider $j$.

$$
A_{i}=\sum_{j \in\left\{d_{i j} \in D_{r}\right\}} R_{j} W_{r}
$$

The second step is shown in Equation (2), where $A_{i}$ calculates the accessibility of the population at $i$ to $\mathrm{MH}$ service providers, $\mathrm{R}_{j}$ is the service provider-topopulation ratio at provider location $\mathrm{j}$ within the catchment of population $i$, and $d_{i j}$ as the travel time between $i$ and $j$.

\section{Calculating accessibility}

Using the USWFCA ArcGIS Add-In tool, the E2SFCA accessibility scores to mental health services were calculated for eight separate scenarios (Table 1). This tool has been successfully used by Frew et al. (2017) and Wang and Ramroop (2018) in modeling potential accessibility to primary health care services based on user assigned input parameters and datasets. The tool takes as input a service supply data set representing the location of mental health service providers with a field selected to indicate the number of physicians or services at each location. The second input is a service demand data set representing the location of populations accessing services which are represented by DA centroids. The tool then takes as input a GIS network data set representing the travel pathways between points of service demand and supply. The user also indicates the travel distance in meters and selects a distance-decay function.

As shown in Table 1, accessibility was modelled in eight scenarios (2 types of $\mathrm{MH}$ service locations $\times 4$ modes of transportation). While community-based mental health services are open to the public, psychiatrists are medical professionals that require service users to receive a referral from a hospital or family physician. In implementing the accessibility model, previous studies of spatial accessibility to health care services have used hypothetical travel time thresholds ranging from 10 to 40 minutes (Lee and Hong, 2013; Luo and Wang, 2003; Wang and Ramroop 2018) or information on travel time or distance from questionnaire surveys (Wang and Roisman, 2011). In this study, for each mode of transportation, different travel distances were used based on an estimated travel time of 10 minutes that has been used in other relevant studies (Langford and Higgs, 2006). This threshold was considered appropriate for the geographical extent of the City of Toronto and for reducing edge effects. The distance threshold used for driving and public transit was 5 kilometers (assuming an average speed of 30 kilometers per hour), a distance of 2 kilometers was used for biking (assuming an average speed of 12 kilometers per hour) and a distance of 1 kilometer for walking (assuming an average speed of 6 kilometers per hour). Across all scenarios, the demand population for each dissemination area was set as the population aged 15 years and above. The distancedecay parameter was set at as a Gaussian distance decay with a bandwidth of 50 . 


\section{Calculating accessibility}

Accessibility scores calculated for each of the eight scenarios were standardized using a Z-Score, to allow for a comparison between the two different types of $\mathrm{MH}$ service providers and for developing a composite score combining the four modes of transportation. The combined accessibility scores were calculated by 1) multiplying the proportion of the population in a DA using a mode of transportation by accessibility $z$ score for the mode of transportation, and 2) summing up for all four modes of transportation. The calculation is shown in Equation (3), where DRIV, WALK, BIKE, PUBT represent the percentage of population in a DA that use the four modes of transportation to work, respectively. Access driving, Access walk, Access bike, Access transit were calculated accessibility scores for each transportation mode. Acknowledging the limitation of using census data on employment-related transportation behaviour in Equation (3), given the absence of empirical information on travel mode in seeking mental health services, census data provided useful insights into the capacity and choice of choosing a specific transportation mode at the DA level. More emphasis was attributed to access scores for predominant forms of transportation resulting in a single accessibility score for each DA.

$$
\begin{aligned}
& \text { Combined Accessibility Score } \\
& \qquad \begin{aligned}
& \left(\text { DRIV } * \text { Access }_{\text {driving }}\right) \\
& +\left(\text { WALK* } \text { Access }_{\text {walk }}\right) \\
& +\left(\text { BIKE } * \text { Access }_{\text {bike }}\right) \\
& +\left(P U B T * \text { Access }_{\text {transit }}\right)
\end{aligned}
\end{aligned}
$$

\section{Measuring association between accessibility and mental health crises}

Calculated accessibility scores (to $\mathrm{MH}$ specialists and $\mathrm{MH}$ community services, respectively) were visualized on maps to reveal variation in levels of access in the City of Toronto. Getis-Ord Gi* statistic was then calculated for three measures (combined accessibility to mental health community services, combined accessibility to mental health specialist, the mental health crisis score) to highlight statistically significant spatial clusters in spatial accessibility and mental health crisis.

Pearson's correlation analysis was used to assess the association between mental health crisis rate and
$\mathrm{MH}$ service accessibility, for community-based and specialist services, respectively. To identify the spatially varying relationship between accessibility and $\mathrm{MH}$ crisis rate, the bivariate local indicator of spatial association (BiLISA) was employed. The BiLISA method is built upon the univariate LISA to measure correlation between one variable and a different variable in nearby areas, which can be represented as a measure of spatial autocorrelation for each location (Anselin et al., 2002; Anselin, 1995). Thus, the method is considered a local version of the correlation coefficient. It is an established spatial technique that has been used to explore spatial autocorrelation that varies over space in various settings such as infectious disease, neighbourhood walkability and road safety (Frank et al., 2010; Borderon et al., 2014; Akbar Matkan et al., 2013). In this study, the BiLISA method was applied to assess the spatial relationship for two pairs of variables outlined in Table 2. Specifically, it identified where high or low values of one variable (e.g., mental health crisis rate) cluster spatially in relation to the values of another variable (e.g., calculated accessibility) in surrounding features, and revealed features with values (of one variable) that were very different from values of another variable in surrounding neighbourhoods. The method is visually intuitive in highlighting the nature and strength of the association between mental health crisis rate and spatial accessibility that varies over the study area.

\section{RESULTS}

\section{Spatial distribution of mental health services and mental health crises}

Within the city of Toronto, both mental health community services and mental health specialists were unevenly distributed and found primarily in areas of high population density (Figures 1 and 2 ). There were a total of 102 community-based $\mathrm{MH}$ service organizations whose primary function is to provide mental health services to surrounding residents. The average density of mental health community services in the City of Toronto was 0.16 organization per $\mathrm{km} 2$. Mental health community services were mostly concentrated in the downtown core in middle and low-income neighbourhoods. In the peripheral areas of the City of Toronto, community services were found at major road intersections where the population density is higher. 
The majority of $\mathrm{MH}$ specialists, or psychiatric physicians, were concentrated in the downtown core where there was a high density of hospitals and healthcare centres. The downtown cluster of mental health specialists extended from King Street and northwards until Eglinton Avenue, bound on the east and west by Bathurst Street and Mount Pleasant Road, known as the former municipality of Toronto. It is important to note that a high concentration of mental health specialists was located in the highincome neighbourhoods of Rosedale, Forest Hill and Casa Loma. There was a total of 718 mental health specialists in the study area, with an average density of 1.1 physicians per $\mathrm{km} 2$. The highest density of mental health specialists was in the neighbourhoods of University, Bay Street Corridor and KensingtonChinatown each with a density of above 30 mental health specialists per $\mathrm{km} 2$.

Between 2014 to 2016, within the City of Toronto a total of 18,338 Mental Health Act (MHA) apprehensions were recorded by the Toronto Police Service with information on the residential address by DA. Apprehension rates, or mental health crisis rates, in DA ranged from 0 to over 1400 apprehensions per 10,000 persons with a mean of 32.58 apprehensions per 10,000 persons (Figure 3). Areas of high apprehension rates concentrated in downtown Toronto, East York, and central parts of North York and Scarborough. The neighbourhoods with DAs showing highest rates of MHA apprehensions were found in the east end of the downtown core in the Bay Street Corridor, Church-Yonge Corridor and Moss Park. Other neighbourhoods of high MHA apprehension rates were Downsview in North York and the Junction area.

\section{Accessibility to mental health community services and medical specialists}

Figure 4 shows the Z-scores for combined accessibility to mental health community services, the highest scores were found in the west end of downtown Toronto as well as the area of North York and downtown Scarborough. Across of the City of Toronto, about $71 \%$ of the DAs had combined accessibility Z-scores of 0 or below, these DAs were mostly located in peripheral neighbourhoods in Scarborough, East York and Etobicoke. Getis-Ord Gi* hotspot analysis of the combined access scores for mental health community services show statistically significant hotspots of high access to mental health community services in a large contiguous area in downtown core of Toronto extending northwest to the former municipalities of York and North York (Figure 5). Other statistically significant hotspots of high access can be found in the periphery of the city. These hotspots of good access to $\mathrm{MH}$ community service DAs were located in North York centred around the York University Heights and Bathurst Manor neighbourhoods, in Scarborough around the Woburn neighbourhood and in the Islington - City Centre West neighbourhood of Etobicoke. Statistically significant cold spots were located in the former municipalities of Scarborough, North York, East York and some regions of Etobicoke.

In the City of Toronto, mental health specialists were more numerous and more evenly spread over space than mental health community services, as such, populations in the City of Toronto had higher levels of spatial access to mental health specialists than mental health community services. The output from the E2SFCA method tool produced for each DA a physician-to-population ratio that serves as a measure of potential spatial accessibility to mental health specialists. The spatial distribution of Z-scores for combined access to mental health specialists are shown in Figure 5, areas of high combined accessibility are spatially clustered in the former municipality of Toronto in a region that extends up towards the south of North York. This area had the largest concentration of hospitals, physicians, and medical facilities. The results from the Getis-Ord Gi* hotspot analysis show a sizeable contiguous hotspot of high access to mental health community services in the downtown core of Toronto. This hotspot that is statistically significant at the $90 \%$ confidence level is comprised of 928 DAs (25.2\% of the City of Toronto) found within the former municipalities of Toronto, and parts of York, East York and North York. Statistically significant cold spots were mostly located in the former municipalities of Scarborough and Etobicoke, with $85 \% .12$ and $88.2 \%$ of their DAs respectively classified as cold spots at the $99 \%$ confidence level. These indicate that Scarborough and Etobicoke extending to the west end of North York are predominately underserviced in terms of combined access to mental health specialists.

\section{Association between accessibility and mental health} crises 
The Pearson's coefficient results show a weak association between rates of mental health crises and combined accessibility (to $\mathrm{MH}$ community services and $\mathrm{MH}$ specialists, respectively), with no correlations above 0.2 or below -0.2 . For example, mental health crisis rates were very weakly correlated with accessibility to $\mathrm{MH}$ specialists $(r=0.050 ; \mathrm{p}<0.01)$ and $\mathrm{MH}$ community services $(r=0.054 ; p<0.01)$.

The Local Moran's I bivariate analysis reveals a low Moran's I index (Moran's I = 0.04), which indicates an overall weak spatial association between combined access to $\mathrm{MH}$ community services and rate of mental health crises. However, the spatial clustering of HighHigh, Low-Low, High-Low and Low-High variable pairs in Figure 6 provides insights on the spatially varying relationship between accessibility and $\mathrm{MH}$ crisis rate across. As shown in Table 3, a large percentage of DAs (56.4\%, $54.7 \%$ of DAs for community service and specialists, respectively) are classified as not holding a statistically significant relationship between the two variables $(p<0.1)$. Of the DAs that hold a statistically significant relationship, most fall within a High-High or Low-Low classification, indicating a level of relative spatial match in supply and demand, that is, DAs with high levels of accessibility and high rates of mental health crisis, or, DAs with low levels of accessibility and low rates of mental health crisis. DAs classified as High-Low can be considered underserviced with a high level of mental health crises but a relatively low degree of spatial access to $\mathrm{MH}$ services. These DAs exist at similar levels for both the $\mathrm{MH}$ community service and mental health specialist $(6.1 \%, 6.1 \%$ of DAs). DAs classified as Low-High (5.5\%, 5.9\% of DAs) can be regarded as well-serviced, as the mental crisis rate is low in these areas and combined spatial accessibility to services is relatively high.

With respect to spatial accessibility to $\mathrm{MH}$ community service (Figure 6), the clusters of DAs in High-High and Low-High classes by and large neighbour each other, while Low-Low and High-Low DAs are clustered together spatially. High-High clusters are found primarily in the downtown core of the former Municipality of Toronto, in the neighbourhood of York University Heights, North York and the neighbourhoods of Malvern, Woburn and Morningside in Scarborough. The underserviced DAs (High-Low) are found throughout the former municipalities of Scarborough, East York and North York, in particular, where the average household income is higher than all other categories $(\$ 110,084)$.
This suggests that the neighbourhoods in the City of Toronto that are associated with a high mental crisis rate and low spatial access to $\mathrm{MH}$ community service are predominately middle and high income, contrary to literature that identifies income as a key factor of health access inequality (Bryant et al., 2011; Berkman et al., 2014). This result may be explained by the fact that $\mathrm{MH}$ community services, which are provided by organizations such as community health centres, are strategically located in some lower-income neighbourhoods. Therefore, access to $\mathrm{MH}$ community service is low in neighbourhoods associated with a higher income. There are still notable low-income neighbourhoods that are in High-Low cluster (i.e., under-serviced) in access to $\mathrm{MH}$ community services, including Rouge (Scarborough), Humber Summit (North York) and the low-income neighbourhood of Weston (York).

With respect to spatial accessibility to $\mathrm{MH}$ specialists, a low Moran's I index (Moran's I = 0.05) suggests a weak relationship between $\mathrm{MH}$ crisis rate and combined access to $\mathrm{MH}$ specialists. The spatial distribution of clusters (Figure 6) by DA differ slightly from the results produced for access to $\mathrm{MH}$ community services. High-High DAs where both spatial accessibility and mental health crisis rate are high can be found in clusters in the downtown core extending upward from the municipality of Toronto into York. The High-High DAs are located in close proximity to Low-High DAs (i.e., well-serviced) have a relatively higher average household income $(\$ 124,716$, \$121,566). High-Low DAs (i.e., underserviced) are located in peripheral regions of Etobicoke, North York and Scarborough. As shown in Table 3 these underserviced DAs are less affluent with an average household income of $\$ 86,753$, compared to $\$ 121,566$ for well-serviced DAs. This is in line with the literature indicating that social determinants such as income are important factors of inequalities in health and access to healthcare services (Wang and Luo, 2005). Notable underserviced low-income DAs are located in the Toronto Neighbourhoods of Wexford/Maryvale and Dorset Park (Scarborough), Downsview (North York) and Weston (York).

\section{DISCUSSION}

Mental health is a critically important aspect of public health in Canada, as mental illnesses have been shown to affect a significant proportion of the population (Kates et al., 2011; Vasiliadis et al., 2005). 
The literature on neighbourhood and health suggests that spatial and non-spatial characteristics of an individual's neighbourhood of residence can have an impact on health outcomes, including mental health (Sederer, 2016). One key neighbourhood characteristic is potential spatial or geographical accessibility to mental health services, as spatial accessibility measured by distance and/or travel time can work as either an enabler or barrier to the use of a mental health service (Ngui and Vanasse, 2012). With equitable spatial access to care, mental health outcomes in the general population can be improved as individuals and communities will be able to access the services and support that they need (Fleury et al., 2012; Ghorbanzadeh et al., 2020).

The study employed geospatial methods to measure potential spatial accessibility to mental health service provided by specialists (i.e., psychiatrists) and community organization across dissemination areas in the City of Toronto. Combined accessibility was calculated based on the enhanced 2SFCA method (Luo and Qi, 2009) integrating four modes of transportation modes, using 2011 Census. Calculated spatial accessibility was analyzed in conjunction with data on mental health crisis provided by the Toronto Police Service. Association between spatial accessibility to mental health services and mental health crisis levels was further explored. Under-serviced neighbourhoods with low levels of spatial access and high levels of mental health crises were identified to reveal their socioeconomic characteristics.

As revealed in the study, spatial inequalities across the city in accessing mental health services were visually evident (Figure 5). While higher levels of calculated (combined) accessibility, which considers various transportation modes, were found within the city core where population density is highest, accessibility generally decreases as one moves away from the city core, with a few pockets in the inner suburbs having a relatively high level of access. These patterns were further confirmed in hotspot analysis that revealed statistically significant clusters of high and low levels of access to $\mathrm{MH}$ community services and specialists. This study has also shown that mental health crisis events recorded by the Toronto Police Service were more spread out and higher rates are found in in a few DAs in Toronto downtown, North York, Etobicoke and Scarborough. Although services accessibility was high in the city core, the need for mental health services was found across other areas of the City of Toronto. This spatial mis-match partly explained the weak relationship between accessibility and mental health crisis rate for both community and specialist care. In spite of this, the Local Moran's I bivariate spatial analysis was informative in classifying DAs based on level of accessibility and rate of mental health crises, which enables an identification of neighbourhoods that are deemed underserved, defined as DAs of a low level of service accessibility but a high rate of mental health crisis. Geographically, under-serviced neighbourhoods for $\mathrm{MH}$ community services and $\mathrm{MH}$ specialists were distributed differently and are associated with varying socioeconomic conditions. For example, under-served neighbourhoods for specialists were associated with a low household income, while under-serviced neighbourhoods for $\mathrm{MH}$ community services were found to have a high household income, compared to other neighbourhoods. These findings suggested that neighbourhoods with a higher socioeconomic standing generally have greater spatial access to $\mathrm{MH}$ specialists than to $\mathrm{MH}$ community services, whereas the less affluent neighbourhoods were disadvantaged in seeking services from psychiatrist but have easier spatial access to $\mathrm{MH}$ community services.

By using a geospatial approach, this study produced new knowledge on spatial accessibility to different types of mental health services in the City of Toronto at a detailed spatial resolution dissemination area. Previous work examining mental healthcare access in Toronto has primarily focused on the use of qualitative approach to identify nonspatial barriers to access, such as, an inadequate number of mental health workers, lack of social support, housing, limited mental health awareness and cultural stigma (Fenta et al., 2006; Kirmayer et al., 2011; Wright and Stickley, 2013; Chadwick and Collins, 2015). As such, the geographical focus of the study provided a complementary perspective to the existing literature by revealing spatially explicit accessibility patterns. Additionally, this study represented an attempt to combine multiple modes of transportation in measuring spatial accessibility in order to account for variation in travel preferences. Traditionally, much of the literature examined spatial accessibility to healthcare service for a single or multiple travel distances across one sole transportation network (Guagliardo, 2004; McGrail and Humphrey, 2009; Wang and Luo, 2005; Wang and 
Roisman, 2011; Ngui and Vanasse, 2012; Fernandes et al., 2013; Norris et al., 2014). By using multiple transportation networks and applying weights to accessibility scores based on publicly available census data on transportation mode, this study proposed an enhanced and a more accurate measure of accessibility that accounts for different transportation preferences (Fransen et al., 2015). Finally, the study analyzed accessibility scores calculated at the level of dissemination area, a fine areal unit that allows for increased accuracy in results compared to other studies of accessibility based on a census tract level (Bell et al., 2013; Wan et al., 2012). Findings from the study provided timely and valuable implications as they allow to pinpoint small areas with limited spatial accessibility to mental health services. They have potential to contribute to strategic planning for enhancing the delivery of care across city neighbourhoods to those experiencing mental health crisis. For example, the results and methodology of this study would be useful for public health initiatives that seek to increase mental health service utilization among the most vulnerable populations in Toronto, and the spatial accessibility scores can be used directly to inform service planning for the allocation of needed mental health specialist service in underserved areas.

The study has a number of possible limitations. Firstly, the analysis only measured potential spatial accessibility to mental health services. As a result, the results do not account for a myriad of factors that may influence the use of mental health services. For example, language and cultural barriers (Zhao et al., 2021), user preference (Fransen et al., 2015) and cost of access, and attitudinal barriers (Sareen et al., 2007) are important factors that are beyond the scope of this research. Thomson et al. (2015) and Fenta et al. (2006) identify limited awareness and a lack of language-diverse services as systematic barriers to accessing mental health services among ethnic immigrant populations of Toronto. Other limitations of the study relate specifically to the methodology. While the City of Toronto is bordered on the east, west and north boundaries with other municipalities, travel to mental healthcare providers beyond the city boundaries are not accounted for in the study. Furthermore, the use of mental health services within the City of Toronto by populations residing beyond the boundary was not considered. These edge effects would likely result in an underestimation or overestimation of accessibility scores in DAs on the extremity of the study area. In addition, several assumptions exist within the E2SFCA method and the travel distances selected in this analysis are hypothetical. When combining the access scores by mode of transportation there was an assumption that the travel habits of employed adults above the age of 15 years reflect the travel preferences of the entire population. Another limitation concerns the focus on psychiatrists in the study who represent mental health specialists. Primary care or family physicians who may provide various levels of mental health services to their patients are not considered in this study. The omission of family physicians was largely due to the lack of knowledge regarding which family physicians are equipped to adequately treat mental health patients effectively (Collins et al., 2006; Fleury et al., 2012). When implementing the accessibility model, information on size, service attractiveness and capacity is limited, and as a result, there is no differentiation between the capacity of different health service providers. Another limitation lies in the definition of major mental health crisis events, which are provided by the Toronto Police Service. Acknowledging there are likely other mental health crises not captured in the data, the unavailability of mental health status data with a decent spatial resolution remains to be largely scant due to privacy concerns. In addition, age-specific mental health crisis data are not available to the study, and not including children and those under the age of 15 limits the study to examine mental health service access among children. Although the rate of severe mental health incidences involving children would be dramatically lower, accessing child mental health services can be quite challenging. Community mental health, family and youth involvement in treatment and case management are found to be particularly effective in supporting child mental health (Tobon et al., 2015). This points to a future research avenue exploring the spatial accessibility to child mental health services.

The study leads to several other directions in future research. One potential area to explore is the question of how levels of potential spatial accessibility to mental health services relate to perceived level of access to mental health services. Through the use of surveys, data could be collected to better understand this as well as the major nonspatial factors that prevent or facilitate access to mental health services. Further studies are needed to establish a refinement of model parameters related to accessing mental health services for those 
undergoing significant mental health challenges. Information such as mode of transportation preferences and travel distances could also be collected using primary data collection to better inform the travel behavioural assumption used in modelling spatial accessibility. Qualitative data from interviews or focus groups could provide additional critical insight into the understanding of possible enablers and barriers of mental health service access (particularly those related to language, culture, attitude, cost, social network, neighbourhood environment), severe mental health event experiences and coping strategies. Such in-depth qualitative information would greatly complement the general patterns and trends revealed by a spatialquantitative analysis. Future research can improve the spatial accessibility model by gathering additional data on primary care physicians that are able to provide adequate mental health services, and data measuring the attractiveness and capacity of mental health providers (e.g., number of employees, wait time). Using the spatial-quantitative methodological framework developed in the study, future research can be conducted for other police jurisdictions, cities and regions. This would allow for a comparison among different jurisdictions or urban centres and between rural and urban areas where the geographical distribution of mental health services and population demographic can vary greatly.

\section{ACKNOWLEDGEMENT}

The authors wish to acknowledge the Toronto Police Service for providing the data for this Project and lan Williams for supporting graduate student research and placement where initial research ideas emerged. The authors would also like to thank the anonymous reviewers for their thoughtful comments and helpful suggestions that have further improved the paper and expanded the scope.

\section{REFERENCES}

Allen, J., Balfour, R., Bell, R., \& Marmot, M. (2014). Social determinants of mental health. International Review of Psychiatry, 26(4), 392-407.

Bell, S., Wilson, K., Bissonnette, L., \& Shah, T. (2013). Access to Primary Health Care: Does Neighborhood of Residence Matter? Annals of the Association of American Geographers, 103(1), 85-105.
Berkman, L., Kawachi, I. \& Glymour, M. (2014). Social epidemiology. Oxford: Oxford University Press.

Billi, J. E., Pai, C. W., \& Spahlinger, D. A. (2007). The effect of distance to primary care physician on health care utilization and disease burden. Health Care Management Review, 32(1), 22-29.

Bissonnette, L., Wilson, K., Bell, S., \& Shah, T. I. (2012). Neighbourhoods and potential access to health care: The role of spatial and aspatial factors. Health and Place, 18(4), 841-853.

Borum, R. (2000). Improving high risk encounters between people with mental illness and the police. The journal of the American Academy of Psychiatry and the Law, 28(3), 332.

Bracke, P., Delaruelle, K., \& Verhaeghe, M. (2019). Dominant cultural and personal stigma beliefs and the utilization of mental health services: A cross-national comparison. Frontiers in Sociology, 4, 40-40. https://doi.org/10.3389/fsoc.2019.00040

Bryant, T., Raphael, D., Schrecker, T., \& Labonte, R. (2011). Canada: A land of missed opportunity for addressing the social determinants of health. Health Policy, 101(1), 44-58.

Cao, Y., Stewart, K., \& Kalil, R. (2016). Geographic patterns of end-stage renal disease and kidney transplants in the Midwestern United States. Applied Geography, 71, 133-143.

Chadwick, K. A., \& Collins, P. A. (2015). Examining the relationship between social support availability, urban centre size, and selfperceived mental health of recent immigrants to Canada: A mixed-methods analysis. Social Science \& Medicine, 128, 220-230.

Coleman, T. G., \& Cotton, D. (2016). A strategic approach to police interactions with people with a mental illness. Journal of Community Safety \& Well-Being, 1(2), 7-11.

Corrigan, P. W., Druss, B. G., \& Perlick, D. A. (2014). The impact of mental illness stigma on seeking and participating in mental health care. Psychological Science in the Public Interest, 15(2), 37-70. https://doi.org/10.1177/152910061453139 81

Donohoe J, Marshall V, Tan X, Camacho FT, Anderson R, Balkrishnan R. (2016) Evaluating and comparing methods for measuring spatial 
access to mammography centers in Appalachia. Health Services and Outcomes Research Methodology. 6:22-40.

Durbin, A., Sirotich, F., Antoniou, T., Roesslein, K., Durbin, J., \& Lunsky, Y. (2016). Unmet needs among men with human immunodeficiency virus in community mental health care: $A$ cross-sectional study. AIDS Care, 28(7), 878883.

https://doi.org/10.1080/09540121.2016.11 54133

Elliott, Katherine P., and John Hunsley. (2015) "Evaluating the measurement of mental health service accessibility, acceptability, and availability in the Canadian Community Health Survey." American Journal of Orthopsychiatry 85.3: 238.

Farber, S., Morang, M. Z., \& Widener, M. J. (2014). Temporal variability in transit-based accessibility to supermarkets. Applied Geography, 53, 149-159.

Fenta, H., Hyman, I., \& Noh, S. (2006). Mental health service utilization by Ethiopian immigrants and refugees in Toronto. The Journal of Nervous and Mental Disease, 194(12), 925934.

Fernandes, B.D., Lirio A.F., Randow De Freitas, R., and Melchiors, A. (2013). Use of Spatial Analysis to Assess Geographic Accessibility of Community Pharmacies in Sao Mateus. Pharmacology and Pharmacy, 4, 438-442.

Fleury, M. J., Grenier, G., Bamvita, J. M., Perreault, M., Kestens, Y., \& Caron, J. (2012). Comprehensive determinants of health service utilisation for mental health reasons in a Canadian catchment area. International Journal for Equity in Health, 11(1), 20.

Fortney, J., Rost, K., Zhang, M., \& Warren, J. (1999). The impact of geographic accessibility on the intensity and quality of depression treatment. Medical Care, 37(9), 884-93.

Fransen, K., Neutens, T., Farber, S., De Maeyer, P., Deruyter, G., \& Witlox, F. (2015). Identifying public transport gaps using time-dependent accessibility levels. Journal of Transport Geography, 48, 176-187.

Frew, R., Higgs, G., Harding, J., \& Langford, M. (2017). Investigating geospatial data usability from a health geography perspective using sensitivity analysis: The example of potential accessibility to primary healthcare. Journal of Transport \& Health.
Fryers, T., \& Brugha, T. (2013). Childhood Determinants of Adult Psychiatric Disorder. Clinical Practice \& Epidemiology in Mental Health, 9, 1-50.

Ghorbanzadeh, M., Kim, K., Ozguven, E. E., \& Horner, M. W. (2020). A comparative analysis of transportation-based accessibility to mental health services. Transportation research part D: transport and environment, 81, 102278.

Gray, J.E., Shone, M.A., \& Liddle, P.F. (2008). Canadian mental health law and policy (2nd ed.). Markham, Ontario: LexisNexis.

Guagliardo, M. F. (2004). Spatial accessibility of primary care: concepts, methods and challenges. International Journal of Health Geographics, 3(1), 3.

lacobucci, F. (2014). Police encounters with people in crisis: An independent review conducted by the Honourable Frank lacobucci for Chief of Police William Blair, Toronto Police Service. Toronto Police Service.

Jackson, R. J., Dannenberg, A. L., \& Frumkin, H. (2013). Health and the built environment: 10 years after. American Journal of Public Health, 103(9), 1542-1544.

Jorm, A. F. (2012). Mental health literacy: empowering the community to take action for better mental health. The American Psychologist, 67(3), 231-43.

Kates, N., Craven, M. A., Crustolo, A. M., Nikolaou, L., Allen, C., \& Farrar, S. (1997). Sharing care: the psychiatrist in the family physician's office. The Canadian Journal of Psychiatry, 42(9), 960-965.

Kates, N., Mazowita, G., Lemire, F., Jayabarathan, A., Bland, R., Selby, P., ... \& Audet, D. (2011). The evolution of collaborative mental health care in Canada: A shared vision for the future. Canadian Journal of Psychiatry, 56(5), I1.

Kim, J. (2010). Neighborhood disadvantage and mental health: The role of neighborhood disorder and social relationships. Social Science Research, 39(2), 260-271.

Kirmayer, L. J., Narasiah, L., Munoz, M., Rashid, M., Ryder, A. G., Guzder, J., ... Pottie, K. (2011). Common mental health problems in immigrants and refugees: General approach in primary care. Canadian Medical Association Journal, 183(12), E959-67.

Lamb, H. R., Weinberger, L. E., \& DeCuir Jr., W. J. (2002). The police and mental health. Psychiatric Services, 53(10), 1266-1271. 
Langford, M., \& Higgs, G. (2006). Measuring Potential Access to Primary Healthcare Services: The Influence of Alternative Spatial Representations of Population. The Professional Geographer, 58(3), 294-306.

Lee, G., \& Hong, I. (2013). Measuring spatial accessibility in the context of spatial disparity between demand and supply of urban park service. Landscape and Urban Planning, 119, 85-90.

Lorenc, T., Clayton, S., Neary, D., Whitehead, M., Petticrew, M., Thomson, H., Cummins, S., Sowden, A., \& Renton, A. (2012). Crime, fear of crime, environment, and mental health and wellbeing: Mapping review of theories and causal pathways. Health and Place, 18(4), 757-765.

Luo, J. (2016). Analyzing potential spatial access to primary care services with an enhanced floating catchment area method. Cartographica, 51(1), 12-24.

Luo, W., \& Qi, Y. (2009). An enhanced two-step floating catchment area (E2SFCA) method for measuring spatial accessibility to primary care physicians. Health \& Place, 15(4), 11001107.

Luo, W., \& Wang, F. (2003). Measures of spatial accessibility to health care in a GIS environment: synthesis and a case study in the Chicago region. Planning and Design, 30, 865-884.

Mair, Christina, Ana V. Diez Roux, and Jeffrey D. Morenoff. (2010) "Neighborhood stressors and social support as predictors of depressive symptoms in the Chicago Community Adult Health Study." Health \& place 16.5: 811-819.

Mao, L., \& Nekorchuk, D. (2013). Measuring spatial accessibility to healthcare for populations with multiple transportation modes. Health \& place, 24, 115-122.

Matkan, A. A., Shahri, M., \& Mirzaie, M. (2013, September). Bivariate Moran's I and LISA to explore the crash risky locations in urban areas. In Proceedings of the Conference of Network-Association of European Researchers on Urbanisation in the South, Enschede, The Netherlands (pp. 12-14).

McGrail, M. R. (2012). Spatial accessibility of primary health care utilising the two step floating catchment area method: an assessment of recent improvements. International Journal of Health Geographics, 11(1), 50.

McKee-Ryan, F., Song, Z., Wanberg, C. R., \& Kinicki, A. J. (2005). Psychological and physical wellbeing during unemployment: a metaanalytic study. Journal of Applied Psychology, 90(1), 53.

Neutens, T. (2015). Critical Review Accessibility, equity and health care: review and research directions for transport geographers. Journal of Transport Geography, 43, 14-27.

$\mathrm{Ng}$, E., \& Zhang, H. (2020). The mental health of immigrants and refugees: Canadian evidence from a nationally linked database. Health Reports, 31(8), 3-12.

Ngui, A. N., \& Vanasse, A. (2012). Assessing spatial accessibility to mental health facilities in an urban environment. Spatial and Spatiotemporal Epidemiology, 3(3), 195-203.

Norris, P., Horsburgh, S., Sides, G., Ram, S., \& Fraser, J. (2014). Geographical access to community pharmacies in New Zealand. Health \& Place, 29, 140-145.

Paul, K. I., \& Moser, K. (2009). Unemployment impairs mental health: Meta-analyses. Journal of Vocational behavior, 74(3), 264-282.

Sareen, J., Jagdeo, A., Cox, B. J., Clara, I., ten Have, M., Belik, S. L., de Graaf, R., \& Stein, M. B. (2007). Perceived barriers to mental health service utilization in the United States, Ontario, and the Netherlands. Psychiatric services, 58(3), 357-364.

Sederer, L. I. (2016). The Social Determinants of Mental Health. Psychiatric Services, 67(2), 234-235.

Shah, T. I., Bell, S., \& Wilson, K. (2016). Spatial Accessibility to Health Care Services: Identifying under-Serviced Neighbourhoods in Canadian Urban Areas. PLoS ONE, 11(12).

Smetanin, P., Briante, C., Stiff, D., Ahmad, S., \& Khan, M. (2015). The life and economic impact of major mental illnesses in Canada. Mental Health Commission of Canada. Report.

Stergiopoulos, V., Gozdzik, A., Tan de Bibiana, J., Guimond, T., Hwang, S. W., Wasylenki, D. A., \& Leszcz, M. (2016). Brief case management versus usual care for frequent users of emergency departments: The coordinated access to care from hospital emergency departments (CATCH-ED) randomized controlled trial. BMC Health Services Research, 16(1), 432-432. 
https://doi.org/10.1186/s12913-016-1666-1 Link

Thomson, M. S., Chaze, F., George, U., \& Guruge, S. (2015). Improving immigrant populations' access to mental health services in Canada: a review of barriers and recommendations. Journal of immigrant and minority health, 17(6), 1895-1905.

Tobon, J.I., Reid, G.J. \& Brown, J.B. Continuity of Care in Children's Mental Health: Parent, Youth and Provider Perspectives. Community Ment Health J 51, 921-930 (2015). https://doiorg.ezproxy.lib.ryerson.ca/10.1007/s10597015-9873-5

Vasiliadis, H. M., Lesage, A., Adair, C., \& Boyer, R. (2005). Service use for mental health reasons: cross-provincial differences in rates, determinants, and equity of access. The Canadian Journal of Psychiatry, 50(10), 614-619.

Vigo, D., MD, Thornicroft, G., Prof, \& Atun, R., Prof. (2016). Estimating the true global burden of mental illness. The Lancet. Psychiatry, 3(2), 171-178.

Wan, N., Zou, B., \& Sternberg, T. (2012). A three-step floating catchment area method for analyzing spatial access to health services. International Journal of Geographical Information Science, 26(6), 1073-1089.

Wang L., (2015), Immigrant Health Services and Healthcare, in Bauder H. \& Shields J. (Eds.) Immigrant Experiences in North America, Canadian Scholars' Press Inc. pp 343-366

Wang L., Lara Palacios E., (2017), The Social and Spatial Patterning of Life Stress among Immigrants in Canada. Journal of Immigrant and Minority Health 19:665-673

Wang L., Ramroop S., (2018), Accessibility to community pharmacies in the Greater Toronto Area among vulnerable populations, Can J Public Health (CJPH) 109 (5-6): 821-832

Wang, F., \& Luo, W. (2005). Assessing spatial and nonspatial factors for healthcare access: towards an integrated approach to defining health professional shortage areas. Health \& Place, 11(2), 131-146.

Wang, L., \& Roisman, D. (2011). Modeling spatial accessibility of immigrants to culturally diverse family physicians. The Professional Geographer, 63(1), 73-91.
Wright, N., \& Stickley, T. (2013). Concepts of social inclusion, Exclusion and mental health: A review of the international literature. Journal of Psychiatric and Mental Health Nursing, 20(1), 71-81.

Zhao, Y., Segalowitz, N., Voloshyn, A., Chamoux, E., \& Ryder, A. G. (2021). Language barriers to healthcare for linguistic minorities: The case of second language-specific health communication anxiety. Health communication, 36(3), 334-346. 
International Health Trends and Perspectives

Table 1. Eight scenarios for modeling E2SFCA accessibility to mental health services

\begin{tabular}{|c|c|c|c|c|}
\hline Scenario Name & Service supply & Service demand & Network dataset & $\begin{array}{l}\text { Travel distance } \\
\text { (kilometres) }\end{array}$ \\
\hline S1 & \multirow{4}{*}{$\begin{array}{c}\text { Mental health } \\
\text { community services } \\
\text { (211 Toronto) }\end{array}$} & \multirow{8}{*}{$\begin{array}{l}\text { Total population } \\
\text { aged } 15 \text { years and } \\
\text { older (2011) }\end{array}$} & Roads & 5 \\
\hline S2 & & & Sidewalks & 1 \\
\hline S3 & & & Bikeways & 2 \\
\hline S4 & & & TTC Routes & 5 \\
\hline D1 & \multirow{4}{*}{$\begin{array}{c}\text { Mental health } \\
\text { specialists }\end{array}$} & & Roads & 5 \\
\hline $\mathrm{D} 2$ & & & Sidewalks & 1 \\
\hline D3 & & & Bikeways & 2 \\
\hline D4 & & & TTC Routes & 5 \\
\hline
\end{tabular}


(17P International Health Trends and Perspectives

Table 2. Variable pairs of Local Bivariate Moran's I analysis

\begin{tabular}{|l|l|l|}
\hline Run & $\begin{array}{l}\text { First Variable } \\
(\mathrm{X})\end{array}$ & Second Variable $(\mathrm{Y})$ \\
\hline 1 & MH crisis rate & $\begin{array}{l}\text { Combined Accessibility to } \mathrm{MH} \text { community } \\
\text { services }\end{array}$ \\
\hline 2 & MH crisis rate & Combined Accessibility to MH specialists \\
\hline
\end{tabular}

Note: All variables are measured using standardized Z-Scores 
International Health Trends and Perspectives

Table 3. Moran's I bivariate analysis: MHA apprehensions-combined access

\begin{tabular}{|c|c|c|c|c|c|c|}
\hline \multirow{2}{*}{$\begin{array}{l}\text { Bivariate } \\
\text { clusters }\end{array}$} & \multicolumn{3}{|c|}{$\begin{array}{l}\text { Combined Access to } \mathrm{MH} \text { Community } \\
\text { Service }\end{array}$} & \multicolumn{3}{|c|}{ Combined Access to MH Specialist } \\
\hline & $\%$ of DAs & $\begin{array}{l}\text { Population } \\
\text { (\%) }\end{array}$ & $\begin{array}{l}\text { Average } \\
\text { household } \\
\text { income }\end{array}$ & $\%$ of DAs & $\begin{array}{l}\text { Population } \\
\text { (\%) }\end{array}$ & $\begin{array}{l}\text { Average } \\
\text { household } \\
\text { income }\end{array}$ \\
\hline $\begin{array}{l}\text { High-High } \\
\text { High demand } \\
\text { - high access }\end{array}$ & $5.0 \%$ & $\begin{array}{l}115,881 \\
(4.4 \%)\end{array}$ & $\$ 81,510$ & $5.0 \%$ & $\begin{array}{l}121,145 \\
(4.6 \%)\end{array}$ & $\$ 124,716$ \\
\hline $\begin{array}{l}\text { Low-Low } \\
\text { Low demand } \\
\text { - low access }\end{array}$ & $23.5 \%$ & $\begin{array}{l}669,821 \\
(25.6 \%)\end{array}$ & $\$ 90,893$ & $23.5 \%$ & $\begin{array}{l}682,451 \\
(26.1 \%)\end{array}$ & $\$ 79,019$ \\
\hline $\begin{array}{l}\text { Low-High } \\
\text { Well-serviced }\end{array}$ & $9.0 \%$ & $\begin{array}{l}266,924 \\
(10.2 \%)\end{array}$ & $\$ 75,718$ & $10.6 \%$ & $\begin{array}{l}297,438 \\
(11.4 \%)\end{array}$ & $\$ 121,566$ \\
\hline $\begin{array}{l}\text { High-Low } \\
\text { Underservice } \\
d\end{array}$ & $6.1 \%$ & $\begin{array}{l}143,801 \\
(5.5 \%)\end{array}$ & $\$ 110,084$ & $6.1 \%$ & $\begin{array}{l}153,274 \\
(5.9 \%)\end{array}$ & $\$ 86,753$ \\
\hline $\begin{array}{l}\text { Not } \\
\text { Significant }\end{array}$ & $56.4 \%$ & $\begin{array}{l}1,417,976 \\
(54.2 \%)\end{array}$ & $\$ 94,077$ & $54.7 \%$ & $\begin{array}{l}1,360,095 \\
(52.0 \%)\end{array}$ & $\$ 84,851$ \\
\hline
\end{tabular}


Figure 1. Location of community organizations providing mental health services

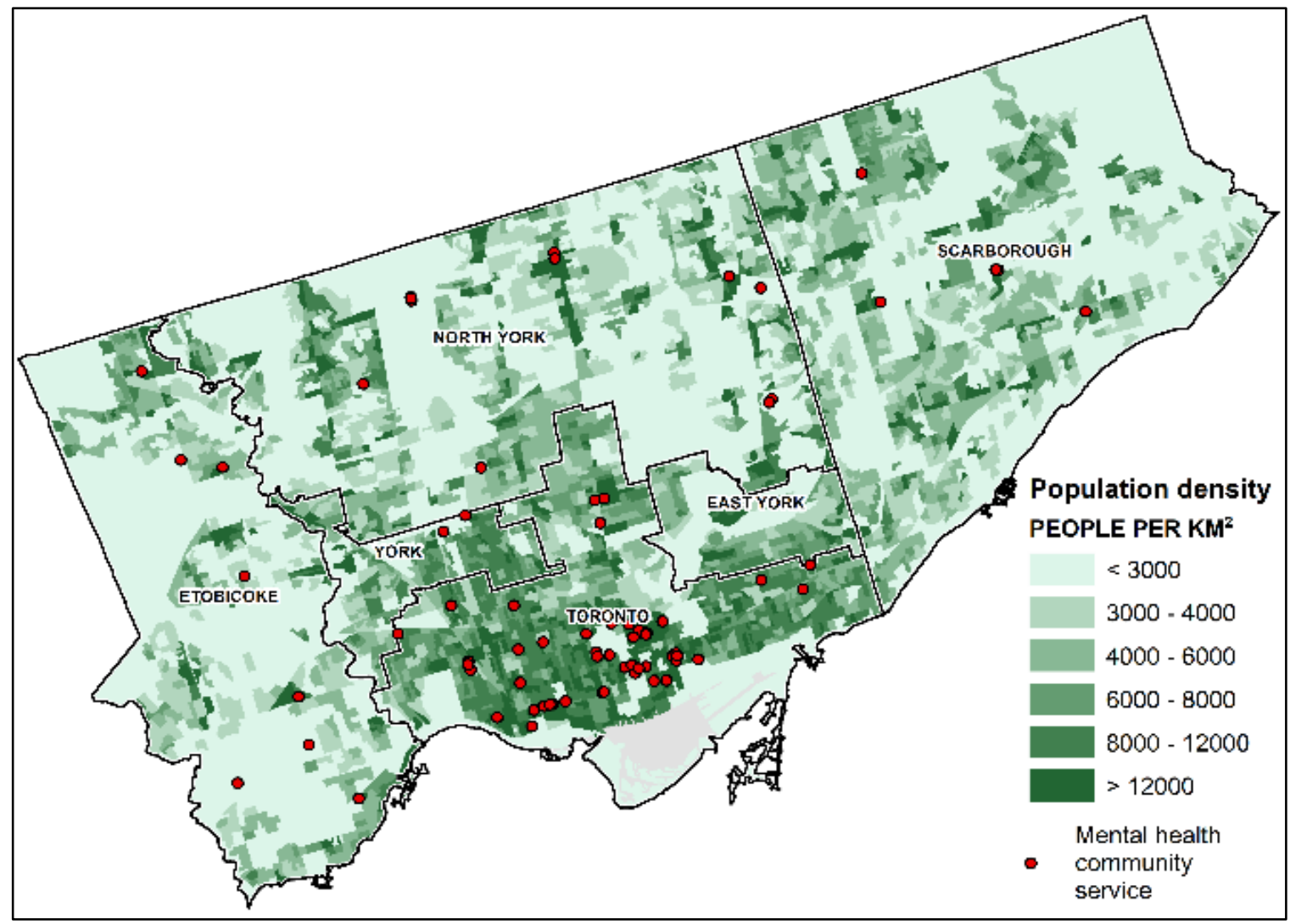


Figure 2. Location of mental health medical specialists (psychiatrists)

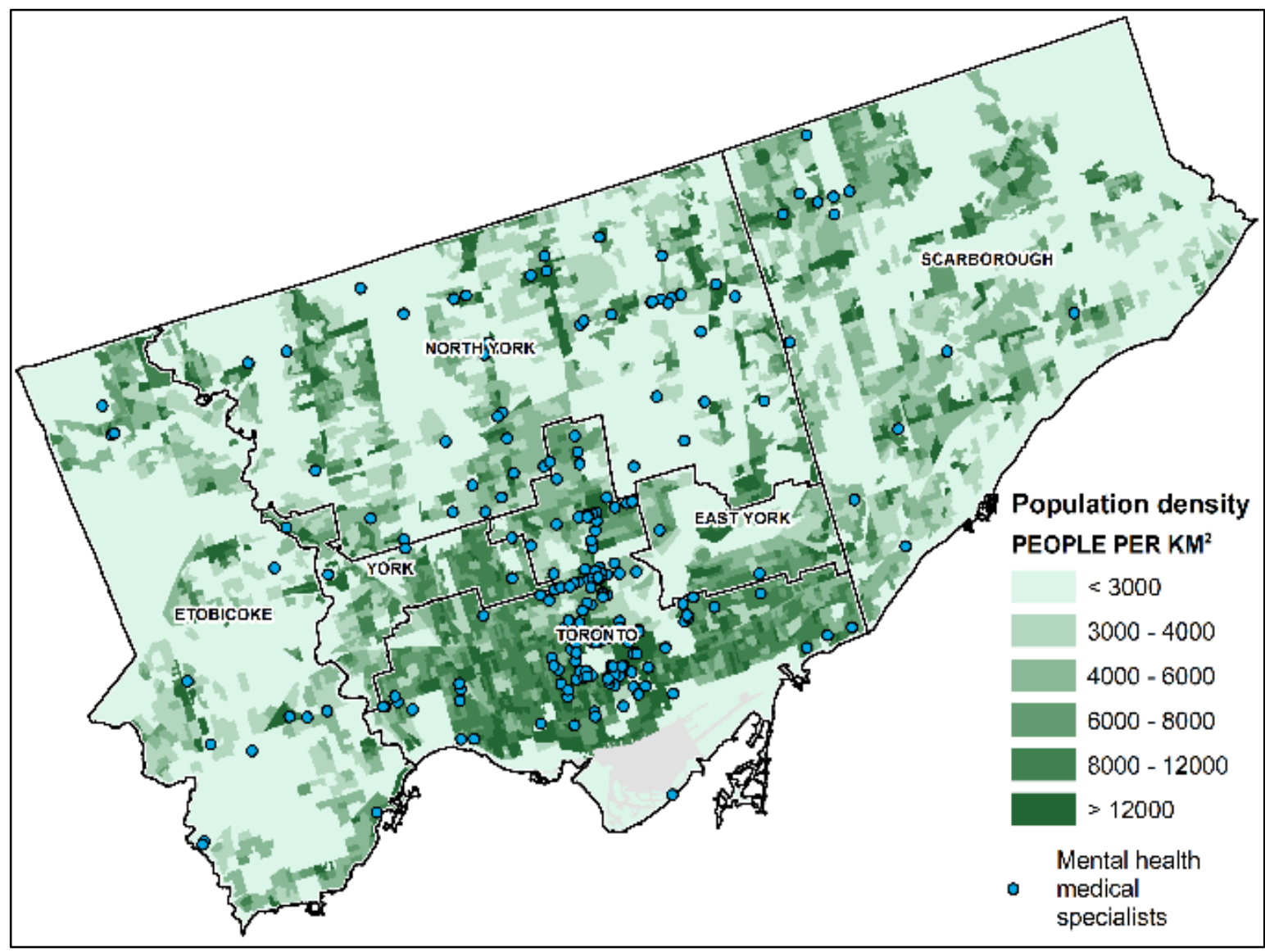


Figure 3. Mental crisis rates among Toronto neighbourhoods

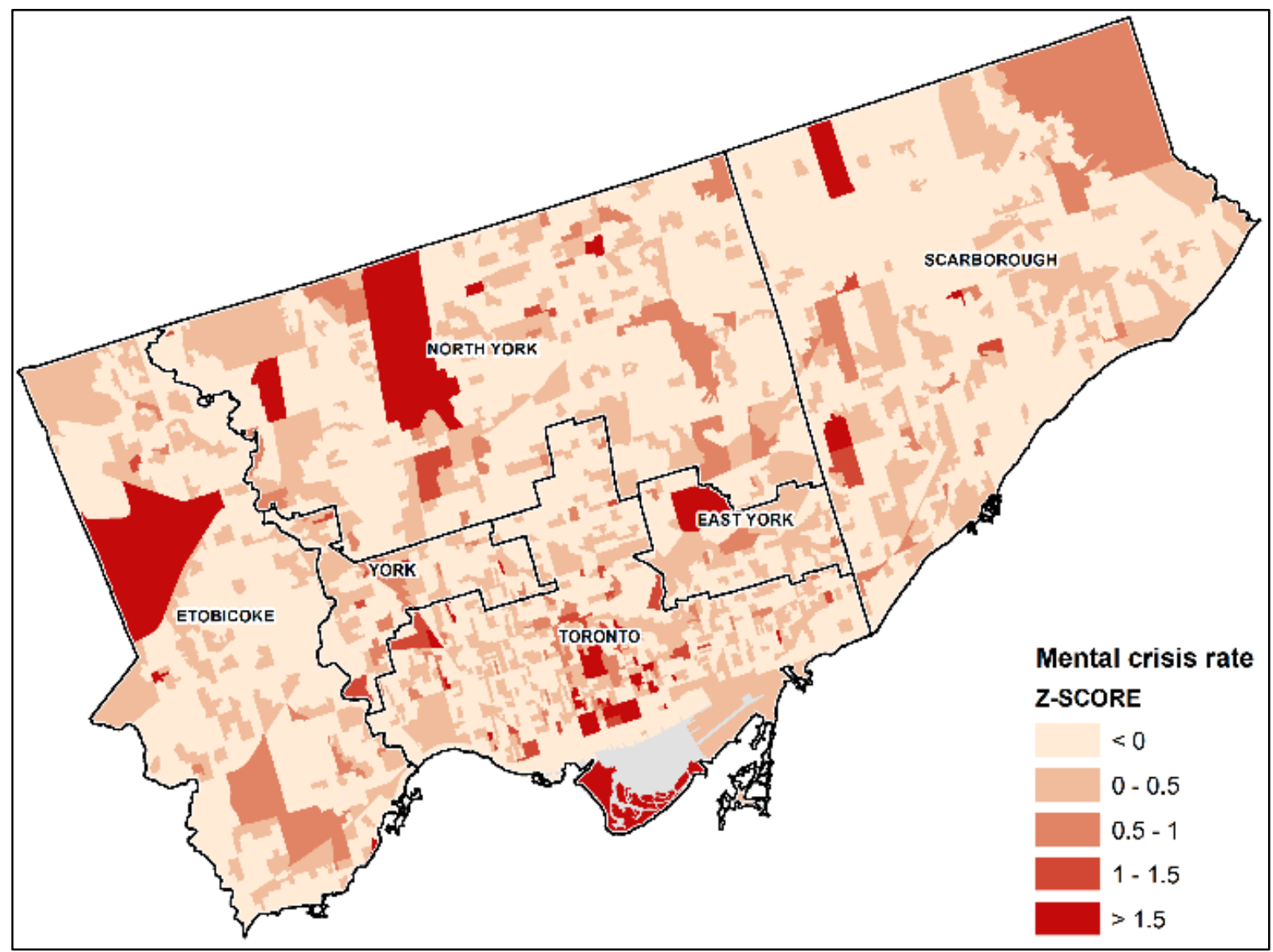


Figure 4. Combined access to mental health community services and specialists

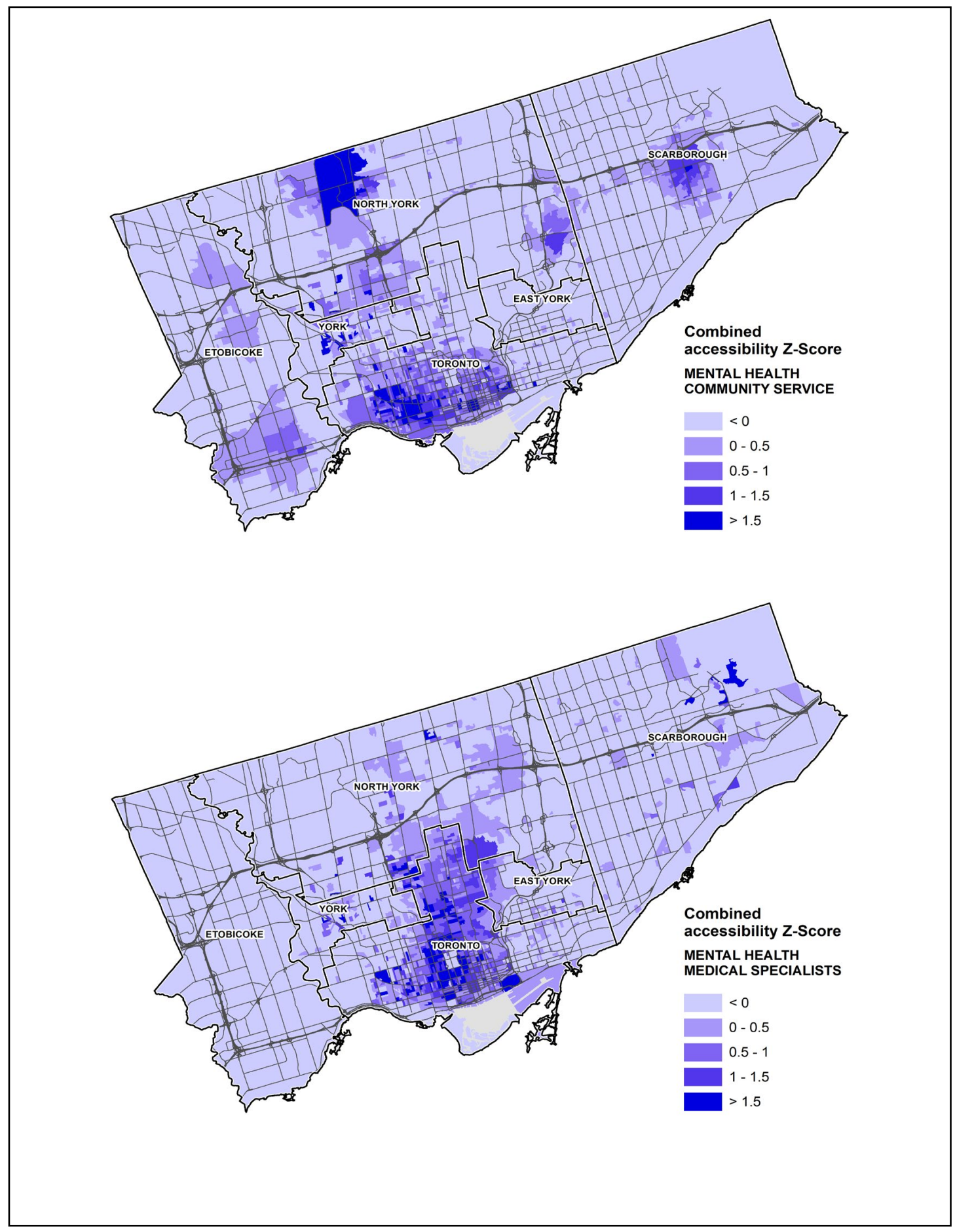


Figure 5. Hotspot map of combined access to mental health community services and specialists
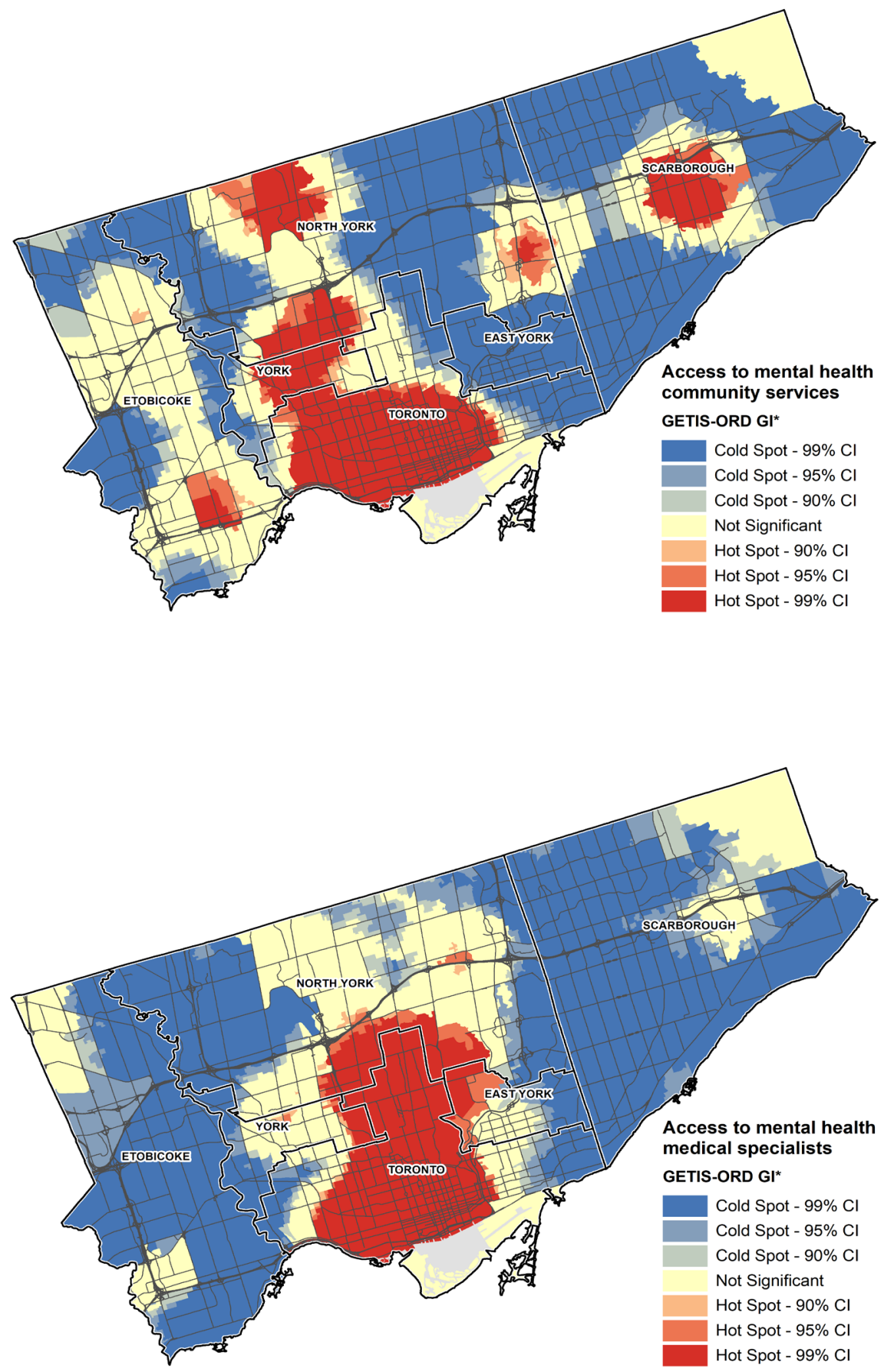
I.

Figure 6. Moran's I cluster map: MHA Apprehensions and Combined access to MH community services and specialists

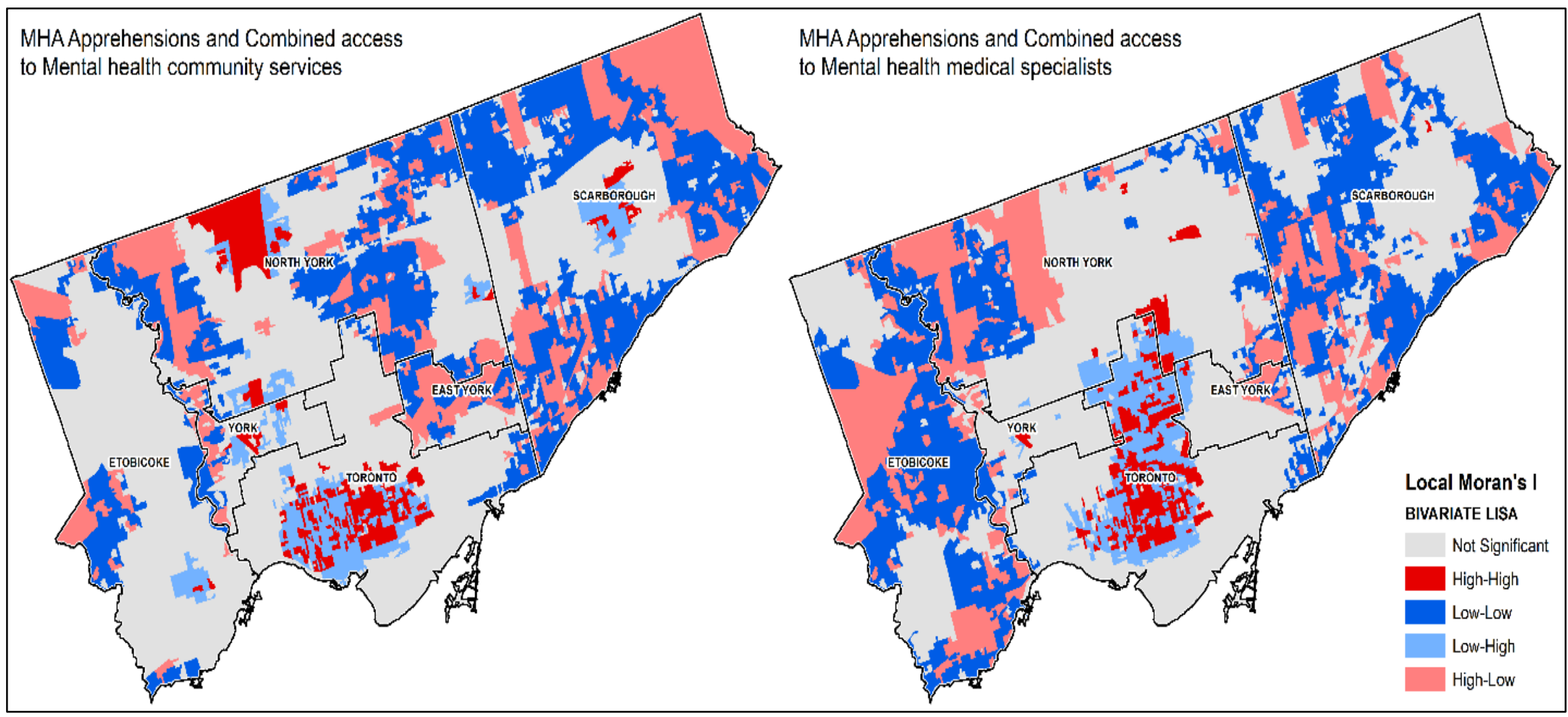

